\title{
Kooperation zwischen Marburg und Nahost
}

Mediziner der Universität Marburger arbeiten in einem trinationalen Verbundprojekt mit israelischen und palästinensischen Arbeitsgruppen zusammen, um gemeinsam die Ursachen des Bauchspeicheldrüsenkrebs' zu erforschen. Möglich wird dies durch eine Finanzierung von Seiten der Deutschen Forschungsgemeinschaft, die speziell trilaterale Projekte unter Beteiligung von deutschen, israelischen und palästinensischen Wissenschaftlern fördert. Ziel ist dabei auch, eine friedliche Entwicklung im Nahen Osten zu unterstützen.

„Mit dem neuen Projekt baut die Medizin der Philipps-Universität ihre starke Stellung in der Forschung zum Bauchspeicheldrüsenkrebs weiter aus", erklärt Prof. Ulrich Koert, Uni-Vizepräsident für Forschung. „Wir freuen uns, dass unsere Uni-Angehörigen mit ihrem Know-how die Zusammenarbeit zwischen israelischen und palästinensischen Kolleginnen und Kollegen fördern können." Neben Prof. Volker Fendrichs Arbeitsgruppe an der PhilippsUniversität beteiligen sich die Teams um Prof. Yuval Dor von „The Hebrew University of Jerusalem" sowie Dr. Areej Khatib vom „Auguste-Viktoria-Hospital“ in Jerusalem an dem Verbund.

\section{Weiterhin schlechte Prognose}

Die Prognose des Patienten mit Pankreaskarzinom ist weiterhin sehr schlecht: Weniger als fünf Prozent der Betroffenen überleben die Diagnose fünf Jahre oder länger. „Die Entstehung des Tumors und insbesondere das Fortschreiten der Erkrankung sind bislang nur unzureichend aufgeklärt", konstatiert der Pankreas-Chirurg Fendrich, der das Vorhaben leitet. „In unserem trilateralen Netzwerk wollen wir zwei zentrale Fragestellungen der Pankreaskarzinombiologie aufgreifen."

\section{Methylierungsmuster soll Auskunft über Herkunft geben}

So möchten die Wissenschaftler herausfinden, woher die Ursprungszelle des Bauchspeicheldrüsenkrebs' stammt. Dafür untersuchen die Forscher unter anderem das Methylierungsmuster in den Zellen, eine chemische Modifikation der Gene, durch die sich Zelltypen voneinander unterscheiden lassen.
In einem weiteren Teilvorhaben nehmen die Projektbeteiligten molekulare Wirkmechanismen unter die Lupe. Hierzu gehört zum Beispiel das krebsunterdrückende Gen BRCA2, das normalerweise für die Reparatur geschädigter DNA zuständig ist. Ist dieses Gen krankhaft verändert, so kann es Bauchspeicheldrüsenkrebs auslösen, wie Fendrich in präklinischen Studien belegen konnte.

„Aufgrund des trinationalen Charakters führt der Verbund das Know-how unterschiedlicher Fachgebiete zusammen. Das erleichtert die Bearbeitung unserer Fragestellungen", so Fendrich. „Die beteiligten Wissenschaftlerinnen und Wissenschaftler bringen Methodenkompetenzen aus Histologie, Genetik und Molekularmedizin in das Netzwerk ein, um einem ursächlichen Verständnis dieser aggressiven Krebserkrankung näher zu kommen."

\section{Informationen:}

Prof. Dr. Volker Fendrich

Fachbereich Medizin/Pankreas-Chirurgie Tel.: 06421 58-69141 und -66443

\section{(Sekretariat)}

E-Mail: fendrich@med.uni-marburg.de

Quelle:

Pressestelle der Philipps-Universität

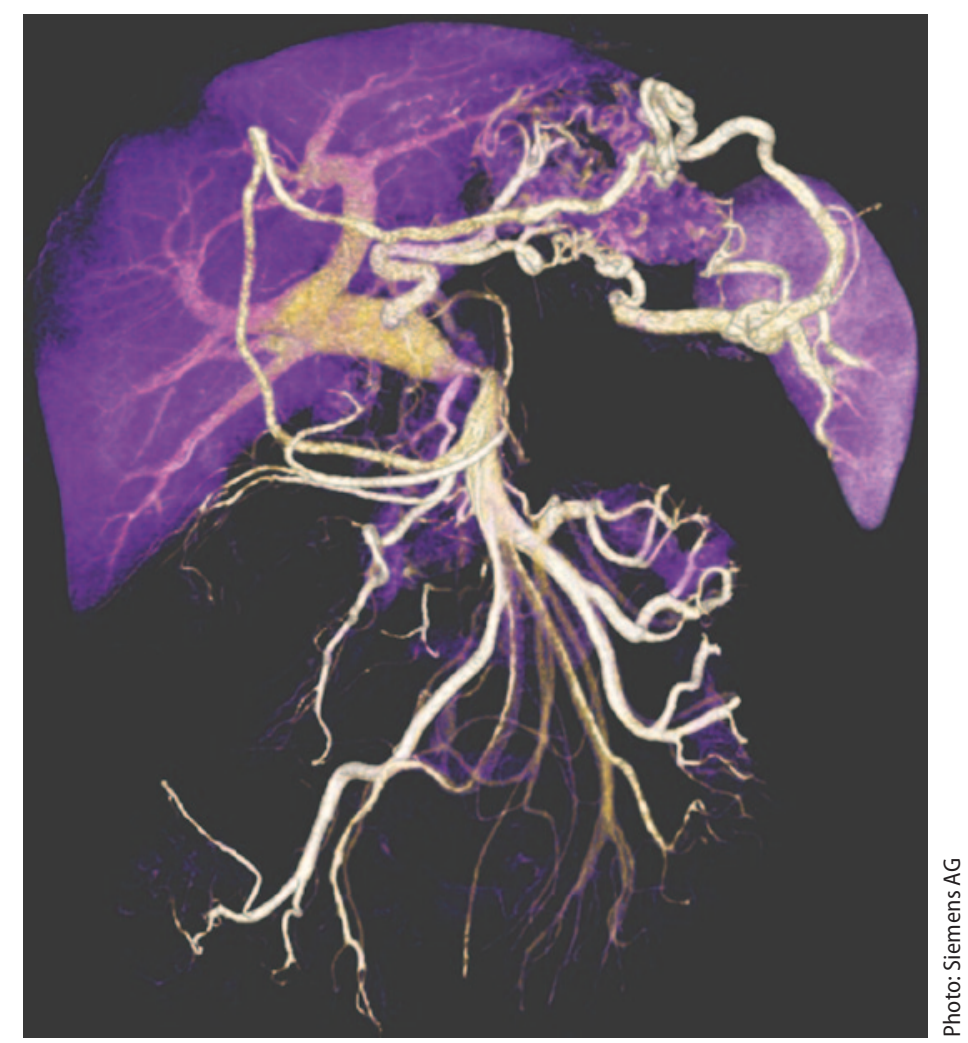

